\title{
Percutaneous Endoscopic Gastrostomy (PEG) Tube Placement in Patients with Continuous-Flow Left Ventricular Assist Devices (LVAD)
}

\author{
Ryan Cobb, Nicholas C. Cavarocchi, Hitoshi Hirose \\ Department of Surgery, Thomas Jefferson University, Philadelphia, USA \\ Email: Hitoshi.Hirose@jefferson.edu
}

Received March 5, 2013; revised April 5, 2013; accepted April 14, 2013

Copyright (C) 2013 Ryan Cobb et al. This is an open access article distributed under the Creative Commons Attribution License, which permits unrestricted use, distribution, and reproduction in any medium, provided the original work is properly cited.

\begin{abstract}
Introduction: Inadequate nutritional support after LVAD placement is known to increase postoperative infections and to decrease survival. LVAD patients with prolonged mechanical ventilation and complicated postoperative recovery requiring prolonged mechanical ventilation may require long-term tube feedings. Placement of a PEG requires knowledge of the location of the LVAD pocket and driveline to avoid device infection and injury. Methods: Between August 2008 and December 2011, 39 patients underwent HeartMate II LVAD placement in our institution. Among them, 5 patients underwent PEG tube placement for long-term nutritional support. Procedure management consisted of cessation of anticoagulation and correction of abnormal coagulation; a cardiothoracic surgeon or intensivist in the operating room to communicate with the surgeon who performed the PEG procedure; and VAD coordinator or perfusionist in the operating room to assist in monitoring the VAD. Data were retrospectively analyzed to investigate complications related to the PEG placement. Results: The studied patients consisted of 3 males and 2 females with mean age of $58+/-5.0$. The interval of LVAD to PEG placement was a mean $21+/-8.8$ days. PEG was successfully performed in the operating room in all patients. There were no LVAD device or driveline injuries related to the PEG procedure. There were no postoperative short-term or long-term PEG related complications such as acute gastric bleeding or dislodgement of the PEG tube. Conclusions: PEG placement for HeartMate II LVAD patients can be done without increasing the risk of device or intraabdominal organ injury with carefully coordinated efforts from both the mechanical support team and surgical services.
\end{abstract}

Keywords: Heart Failure; Mechanical Support Device; Nutrition; PEG

\section{Introduction}

Inadequate nutritional support after LVAD placement is known to increase postoperative infections, to prolong hospitalization, and to decrease survival. The patients in this study had a complicated postoperative recovery period after receiving HeartMate II left ventricular assist devices (LVADs) requiring prolonged mechanical ventilation, which required long-term nutritional support. Post-operative patients with newly implanted LVADs run a high risk of infection, especially with multiple drug-resistant organisms [1]. This patient population's increased susceptibility to infection makes infection prevention one of the top treatment objectives. A stable nutritional status can be the foundation to achieve this goal. Many protocols designed to provide this platform involve the use total parenteral nutrition (TPN) or a nasogastric tubes
(NGT) for long-term feedings.

Both modalities of TPN and NGT tube feeding carry the risk of multiple complications. TPN brings with it a host of complications, including parenteral-associated liver disease and a higher rate of blood-stream infections (BSI), to name a few [2]. The central venous catheters (CVC) required to provide TPN are a direct source of infection, and the number of CVC days in an intensive care unit (ICU) is directly linked to increased rates of bacterial and fungal BSI [3-5]. While NGTs have a lower risk of BSI, they do present with higher risk of aspiration pneumonia, esophagitis, and gastrointestinal bleeding (GIB) [6]. Patients receiving the HeartMate II LVAD are already at an increased risk of GIB; so another route of nutritional support was sought [7].

Percutaneous endoscopic gastrostomy (PEG) tubes are considered as a viable alternative to NGT and TPN for 
long-term nutritional support. Due to the anatomical position of the LVAD pocket and drivelines, the PEG tube placement procedure has the potential to disrupt the aforementioned structures. The potential of an infection at the PEG site compromising the LVAD device is a valid concern. In addition, patients with LVADs require constant anticoagulation. Titrating patients off anticoagulation lead to a concern for thromboembolic events and pump thrombosis. While the HeartMate II LVAD pump has a low rate of thromboembolic events and pump thrombosis, there have been cases of these events occurring [8]. There has been a concern in the past for intraoperative and post-operative bleeding associated with the PEG placement procedure when anticoagulation is continued. At our institution, an LVAD anticoagulation protocol was established to allow for PEG placement with minimal complications. The current study was performed to investigate the feasibility of PEG placement while on anticoagulation for a LVAD.

\section{Methods}

Between August 2008 and December 2011, 39 patients underwent HeartMate II LVAD (Thoratec Co, Pleasanton, CA) placement for end-stage heart failure as either bridge to transplant or destination therapy in our institution. Among them, 5 patients underwent PEG tube placement for long-term nutritional support in the operating room or intensive care unit. Procedure management consisted of cessation of anticoagulation and correction of abnormal coagulation before the procedure; a cardiothoracic surgeon or intensivist in the operating room to communicate with the surgeon who performed the PEG procedure; and VAD coordinator or perfusionist in the operating room to assist in monitoring the VAD. Data were retrospectively analyzed to investigate complications related to the PEG placement. This study was approved by internal review board.

\section{Results}

The studied patients consisted of 3 males and 2 females with mean age of $58+/-5.0$. The interval of LVAD to PEG placement was a mean $21+/-8.8$ days (Table 1). PEG was successfully performed in the operating room or intensive care unit in all patients. There were no LVAD device or driveline injuries during the PEG procedure. There were no postoperative short-term or longterm PEG related complications such as acute gastric bleeding or dislodgement of the PEG tube. No patient developed aspiration pneumonia related to PEG tube feeding after PEG placement (Figure 1).

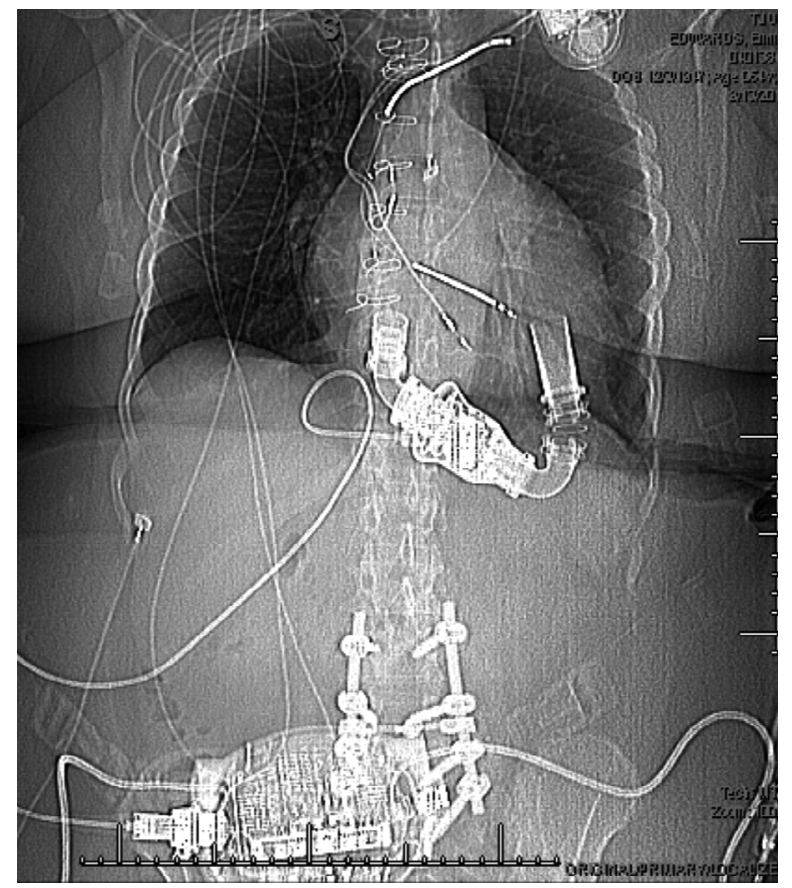

Figure 1. CT scan of the patient with LVAD shows HeartMate II LVAD device and drive line. There is the space for PEG in the right uppermid quadrant.

Table 1. Patient demographics.

\begin{tabular}{|c|c|c|c|c|c|c|c|c|}
\hline$\#$ & Age & Sex & $\begin{array}{c}\text { Destination vs. } \\
\text { bridge to } \\
\text { transplant }\end{array}$ & $\begin{array}{l}\text { PTT at the } \\
\text { time of PEG }\end{array}$ & $\begin{array}{l}\text { Post LVAD } \\
\text { complications } \\
\text { before PEG }\end{array}$ & $\begin{array}{c}\text { LVAD- } \\
\text { PEG (days) }\end{array}$ & Post-PEG & Outcome \\
\hline 1 & 65 & M & $\begin{array}{l}\text { Bridge to } \\
\text { Transplant }\end{array}$ & 36 & $\begin{array}{l}\text { VDRF Renal failure on } \\
\text { CVVHD Multiple sternal } \\
\text { washout due to bleeding }\end{array}$ & 30 & $\begin{array}{l}\text { Sternal wound was healed } \\
\text { and the patient underwent } \\
\text { heart transplantation. }\end{array}$ & Discharged to rehab \\
\hline 2 & 53 & $\mathrm{~F}$ & Destination & 36 & $\begin{array}{l}\text { VDRF, pneumonia } \\
\text { (Preop ECMO due to shock) }\end{array}$ & 13 & $\begin{array}{l}\text { Pneumonia was } \\
\text { treated in success }\end{array}$ & Discharged to rehab \\
\hline 3 & 58 & M & Destination & 32 & $\begin{array}{l}\text { VDRF Renal failure on } \\
\text { CVVHD Stroke Lower GI bleed }\end{array}$ & 17 & No infection. & Discharged to rehab \\
\hline 4 & 62 & $\mathrm{~F}$ & Destination & 37 & VDRF (Preop history of stroke) & 12 & No infection & Discharged to rehab \\
\hline 5 & 52 & M & Destination & 51 & $\begin{array}{l}\text { VDRF, Endocarditis } \\
\text { Renal failure on CVVHD } \\
\text { Cirrhosis of liver }\end{array}$ & 33 & $\begin{array}{l}\text { Unable to control sepsis, } \\
\text { died from sepsis }\end{array}$ & $\begin{array}{l}\text { Expired in hospital } \\
\text { due to sepsis }\end{array}$ \\
\hline
\end{tabular}

CVVHD: continuous veno-veno hemodialysis; ECMO: extracorporeal membrane oxygenation; GI: gastrointestinal; VDRF: ventilator dependent respiratory failure. 


\section{Discussion}

Patients with LVADs receiving a PEG tube for long-term nutritional support with must be maintained on a minimal amount of anticoagulation to prevent thromboembolic events and pump thrombosis while not increasing the risk of bleeding. Thrombotic events must be carefully watched for in continuous-flow LVADs, like the HeartMate II, even though they have lower rates of these complications than the pulsatile flow LVADs [9]. Thrombotic events are not solely feared for their compromise of circulation, but are also linked to increased rates of infection [10].

Bacterial and fungal insults can wreak havoc in LVAD patients causing a multitude of complications that increase morbidity and mortality. One of the main purposes of this study was to reduce the already established infectious risk correlated with CVC required for TPN and gastro-enteric compromise associated with NGTs. One case series elucidated the threat of gastrointestinal-tract fistulas causing critical infections of the LVAD pocket [11]. One can only imagine with the anatomic location of an NGT in the stomach and LVAD pocket within the abdomen, how a small erosion caused by the NGT in the gastric mucosa could communicate with the LVAD pocket. This in turn could lead to devastating rise in infection rates among these patients.

This study provided an alternative nutritional route without direct complication. This was achieved by balancing anticoagulation and hemostasis to prevent intraoperative and post-operative morbidity and mortality in the placement of a PEG tube in patients with LVAD devices. Intra-operative and post-operative bleeding are two immediate concerns in patients on chronic anticoagulation. Compound this with the already existing increased rate of GI bleeding with LVADs, and clinical management becomes more difficult [7]. The anticoagulation protocol followed in this study provided five LVAD patients with PEG tubes without GI bleeds or any other complication related to the PEG procedure.

\section{Conclusion}

PEG placement for HeartMate II LVAD patients can be done without increasing the risk of device or intraabdominal organ injury with carefully coordinated efforts from both the mechanical support team and surgical services.

\section{REFERENCES}

[1] A. Beiras-Fernandez, F. Kur, S. Kiefer, R. Sodian, M. Schmoeckel, M. Weis, B. Reichart and F. Weis, "Multidrug-Resistant Gram-Positive Infections in Patients with Ventricular Assist Devices: The Role of Daptomycin," Transplantation Proceedings, Vol. 41, No. 6, 2009, pp.
2589-2591. doi:10.1016/j.transproceed.2009.06.126

[2] Z. W. Xu and Y. S. Li, "Pathogenesis and Treatment of Parenteral Nutrition-Associated Liver Disease," Hepatobiliary \& Pancreatic Diseases International, Vol. 11, No. 6, 2012, pp. 586-593. doi:10.1016/S1499-3872(12)60229-X

[3] S. P. Yang, Y. Y. Chen, H. H. Hsu, F. D. Wang, L. Y. Chen and C. P. Fung, "A Risk Factor Analysis of Healthcare-Associated Fungal Infections in an Intensive Care unit: A Retrospective Cohort Study," BMC Infectious Diseases, Vol. 13, 2013, p. 10. doi:10.1186/1471-2334-13-10

[4] I. I. Raad and G. P. Bodey, "Infectious Complications of Indwelling Vascular Catheters," Clinical Infectious Diseases, Vol. 15, No. 2, 1992, pp. 197-208.

doi:10.1093/clinids/15.2.197

[5] T. I. van der Kooi, J. C. Wille and B. H. van Benthem, "Catheter Application, Insertion Vein and Length of ICU Stay Prior to Insertion Affect the Risk of Catheter Related Bloodstream Infection," Journal of Hospital Infection, Vol. 80, 2012, pp. 238-244. doi:10.1016/j.jhin.2011.11.012

[6] E. Kostadima, A. G. Kaditis, E. I. Alexopoulos, E. Zakynthinos and D. Sfyras, "Early Gastrostomy Reduces the Rate of Ventilator-Associated Pneumonia in Stroke or Head Injury Patients," European Respiratory Journal, Vol. 26, 2005, pp. 106-111. doi:10.1183/09031936.05.00096104

[7] J. A. Morgan, G. Paone, H. W. Nemeh, S. E. Henry, R. Patel, J. Vavra, C. T. Williams, D. E. Lanfear, C. Tita and R. J. Brewer, "Gastrointestinal Bleeding with the HeartMate II Left Ventricular Assist Device," The Journal of Heart and Lung Transplantation, Vol. 31, No. 7, 2012, pp. 715-718. doi:10.1016/j.healun.2012.02.015

[8] A. L. Meyer, C. Kuehn, J. Weidemann, D. Malehsa, C. Bara, S. Fischer, A. Haverich and M. Strüber, "Thrombus Formation in a HeartMate II Left Ventricular Assist Device," The Journal of Thoracic and Cardiovascular Surgery, Vol. 135, No. 1, 2008, pp. 203-204. doi:10.1016/j.jtcvs.2007.08.048

[9] M. S. Slaughter, J. G. Rogers, C. A. Milano, S. D. Russell, J. V. Conte, D. Feldman, B. Sun, A. J. Tatooles, R. M. Delgado 3rd, J. W. Long, T. C. Wozniak, W. Ghumman, D. J. Farrar and O. H. Frazier, "Advanced Heart Failure Treated with Continuous-Flow Left Ventricular Assist Device," The New England Journal of Medicine, Vol. 361, No. 23, 2009, pp. 2241-2251. doi:10.1097/00002480-200011000-00034

[10] T. J. Myers, T. Khan and O. H. Frazier, "Infectious Complications Associated with Ventricular Assist Systems," ASAIO Journal, Vol. 46, No. 6, 2000, pp. S28-S36.

[11] M. H. Akay, I. Gregoric, W. E. Cohn and O. H. Frazier, "HeartMate-II Left Ventricular Assist Device Infections Resulting from Gastrointestinal-Tract Fistulas," Journal of Cardiac Surgery, Vol. 27, No. 5, 2012, pp. 643-645. doi:10.1111/j.1540-8191.2012.01517.x 